\title{
Anti-infection mechanism of phosphodiesterase-5 inhibitors and their roles in coronavirus disease 2019 (Review)
}

\author{
HAO SU, CHENGQUAN MA and HONGJUN LI
}

\author{
Department of Urology, Peking Union Medical College Hospital, Peking Union Medical College, \\ Chinese Academy of Medical Sciences, Beijing 100730, P.R. China
}

Received October 27, 2020; Accepted January 19, 2021

DOI: $10.3892 /$ etm.2021.9751

\begin{abstract}
Coronavirus disease 2019 (COVID-19) has a variety of impacts on the human body. Severe acute respiratory syndrome coronavirus 2 is the pathogen that causes COVID-19. It invades human tissues through the receptor angiotensin-converting enzyme 2, resulting in an imbalance in the angiotensin II (AngII) level and upregulation of renin-angiotensin system/AngII pathway activity. Furthermore, the binding of AngII to its receptor leads to vasoconstriction, endothelial injury and intravascular thrombosis. In addition, COVID-19 may have adverse effects on male reproductive organs and a marked impact on male reproductive health. Phosphodiesterase-5 inhibitors (PDE5Is) may improve vascular endothelial function, promote testicular and systemic blood circulation and testosterone secretion and enhance epididymal function, as well as sperm maturation and capacitation. PDE5Is may also be of use in the treatment of infectious diseases by enhancing immunity and anti-inflammatory responses and improving vascular endothelial function. Based on the pharmacological mechanism of PDE5Is, they are of unique value in the fight against infectious diseases and may be effective in combination with direct antiviral drugs. The anti-infection mechanisms of PDE5Is and their roles in COVID-19 were reviewed in the present study.
\end{abstract}

\section{Contents}

1. Introduction

2. Adverse effects of COVID-19

3. PDE5Is and their anti-infection mechanisms

4. Roles of PDE5Is in COVID-19

5. Conclusion

Correspondence to: Professor Hongjun Li, Department of Urology, Peking Union Medical College Hospital, Peking Union Medical College, Chinese Academy of Medical Sciences, 1 Shuaifuyuan, Dongcheng, Beijing 100730, P.R. China

E-mail: lihongjun@pumch.cn

Key words: coronavirus disease 2019, phosphodiesterase-5 inhibitors, anti-infection, male reproductive system, combined treatment

\section{Introduction}

Coronavirus disease 2019 (COVID-19) is an emerging and rapidly evolving situation, causing an unprecedented continuous impact on survival and daily life worldwide (1). Severe acute respiratory syndrome coronavirus 2 (SARS-CoV-2) is the pathogen that causes COVID-19 (2). Furthermore, SARS-CoV-2 is mutating, and it appears that numerous vaccines have been developed and are now available. But most vaccines that specifically target the existing SARS-CoV-2 may not be effective against a mutant SARS-CoV-2 (3). In the context of viral infection, the body mainly relies on immune function to eventually eliminate the virus, but treatment for the series of consequences of infection is also essential. Exploration of more effective treatment methods, including comprehensive and combined therapies, is urgently required. Previous studies have indicated that phosphodiesterase-5 inhibitors (PDE5Is) exhibit important anti-infectious disease efficacy and may have multiple mechanisms different from those of direct antiviral therapy. The present study systematically summarized the mechanisms of action and potential combined application value of PDE5Is in the treatment of COVID-19.

\section{Adverse effects of COVID-19}

Unfavourable impacts of COVID-19 on the respiratory system and general health. SARS-CoV-2 invades human cells through the receptor angiotensin-converting enzyme 2 (ACE2). During virus entry into host cells, the spike protein on the envelope of SARS-CoV-2 is cleaved into the $\mathrm{S} 1$ and $\mathrm{S} 2$ subunits. $\mathrm{S} 1$ contains a receptor-binding domain (RBD) that directly binds to the peptidase domain (PD) of ACE2 to allow entry into the host cell (4). The peptidase activity of ACE2 is required for SARS-CoV-2 to enter the host cell's cytoplasm. The cleavage of the RBD in the $\mathrm{C}$-terminus of the $\mathrm{S} 1$ subunit initiates the interaction with the PD of ACE2 (5). The binding of S1 to the receptor ACE2 triggers the cleavage of ACE2 via a disintegrin and metalloprotease 17 (ADAM17)/tumour necrosis factor (TNF)-converting enzyme in the outer domain. In addition, a transmembrane serine protease (TMPRSS2) cleaves the C-terminal domain of ACE2 and the cleavage of ADAM17 and TMPRSS2 (outer domain and inner domain) promotes effective viral entry (6). This process appears to result in the loss of ACE2 receptor function and systemic release of the S1/ACE2 complex. 
ACE receptors are expressed in almost all tissues, while ACE2 is expressed in alveolar epithelial cells and capillary endothelial cells. ACE2 is highly expressed in capillary-rich organs, including the lungs and kidneys, as well as in the intestine and brain (7). ACE regulates the renin-angiotensin-aldosterone system (RAAS). ACE2 balances the harmful effects of the ACE/renin-angiotensin system (RAS) pathway through its downstream ACE2/angiotensin/MAS axis (1-7). The classic activation of angiotensin II (AngII) depends on renin and ACE activity. When the juxtaglomerular apparatus of the afferent glomerular artery is activated, a special protease cleaves prorenin into renin. Renin decomposes angiotensinogen into AngI and ACE catalyses the conversion of AngI into AngII. After AngI is converted into AngII, AngII binds to AngII receptors in the kidneys, adrenal cortex, arterioles and brain. AngII acts on the adrenal cortex and stimulates the release of aldosterone, which leads to the retention of sodium and water, and the binding of AngII to angiotensin II type (AT) receptors leads to vasoconstriction, endothelial damage, intravascular thrombosis and an increased blood volume (8). Moreover, AngII may also effectively induce interleukin (IL)- 6 and TNF- $\alpha$ through serine tyrosine kinase, ERK/JNK-MAPK, G protein-coupled receptor activation or corticosteroid receptor interactions (4). AngII is an effective activator of NADPH oxidase, so it is also an inducer of reactive oxygen species. In addition, AngII may activate neutrophils and macrophages to migrate to affected tissues and inhibit the production of nitric oxide (NO), thus promoting vascular injury (9).

ACE2 acts as a ligand through the MAS1 receptor, which is a $\mathrm{G}$ protein-coupled receptor. ACE2 is a single carboxypeptidase that is able to cleave AngI into Ang1-9 and AngII into Ang1-7 (10). These two peptides have vasodilating, antiproliferative and protective effects mediated by activating the $\mathrm{MAS} / \mathrm{G}$ receptor. The ACE2/Ang1-7/MAS1 axis provides an endogenous reverse regulation in the RAAS to balance the harmful effects of the ACE/AngII/AT1 receptor axis. ACE2 activation may prevent the harmful effects of AngII on cells and organisms, such as cell death, fibrosis, vasoconstriction and thrombosis, that lead to alveolar epithelial injury and respiratory failure $(11,12)$. When SARS-CoV-2 binds to ACE2 and enters pulmonary epithelial cells, the receptor ACE2 is released from the surface of host cells and loses its protective function. The loss of ACE2 activity blocks the production of Ang1-9 and Ang1-7, resulting in an imbalance in the AngII level and the upregulation of RAS/AngII pathway activity. The upregulation of the AngII level leads to vasoconstriction, thrombosis, alveolar epithelial injury and respiratory failure, which eventually leads to the symptoms of COVID-19 in the lungs and even the whole body.

COVID-19 may have adverse effects on the testes and reproductive system. Certain studies have examined the expression pattern of ACE2 in adult human testes at the level of single-cell transcriptomes. ACE2 was indicated to be mainly enriched in spermatogonia, Leydig cells and Sertoli cells. Gene ontology analysis suggested that genes related to virus propagation and transmission were highly enriched in ACE2-positive spermatogonia, while the expression of genes related to male gametogenesis was downregulated. ACE2-positive Leydig and Sertoli cells exhibited increased levels of intercellular junction- and immune-related genes, while the levels of mitochondria- and reproduction-related genes were decreased (13). These results suggested that the human testes are a potential target for SARS-CoV-2. SARS-CoV-2 is likely to bind to the receptor ACE2 on testicular cells, which leads to an imbalance in the AngII level and the upregulation of RAS/AngII pathway activity, resulting in vasoconstriction, thrombosis and activation of the inflammatory system, thus causing damage to testicular cells (14).

A study has reported that SARS-CoV-2 may be detected in the semen of certain patients $(15.8 \%)$ and that SARS-CoV-2 may persist in the male reproductive system, causing harm to this system (15). In another study, a mild COVID-19 infection was not likely to affect testis and epididymis function, but semen parameters did seem impaired after a moderate infection. There is no evidence of SARS-CoV-2 shedding in semen of recovered men or men with an acute COVID-19 infection after a recovery time of 32.7 days on average (16). In addition, pathological analysis of testicular tissues from patients with COVID-19 revealed obvious damage to the seminiferous tubules, decreased interstitial cell counts, as well as mild lymphocyte infiltration and obviously damage to the testicular parenchyma. Although SARS-CoV-2 was not detected in the testes of the vast majority of autopsy cases (90\%) by reverse transcription PCR, there were still certain cases (10\%) in which testis autopsy provided evidence of SARS-CoV-2 (17). Therefore, it is likely that COVID-19 may have adverse effects on the male reproductive system.

\section{PDE5Is and their anti-infection mechanisms}

General. PDE5Is are drugs that effectively improve erectile function. PDE5Is increase the concentration of cyclic guanosine monophosphate (cGMP) by inhibiting the activity of PDE5, resulting in relaxation of the smooth muscle of the penis, which increases the blood flow of the artery in the cavernous body of the penis and produces an erection (18). In addition, PDE5Is protect and repair the vascular endothelium and improve the blood circulation; therefore, they are used in the treatment of cardiovascular diseases (19). The detailed mechanism of action of PDE5Is is presented in Fig. 1. Compared with other similar drugs that improve vascular endothelial function, such as ACE inhibitors, statins, calcium antagonists and $\beta$-receptor blockers, PDE5Is have unique mechanisms to improve vascular endothelial function and numerous advantages, including high effectiveness, more diverse indications, benefits for male reproductive health, as well as only a small number of side effects, which are tolerable. The commonly used PDE5Is include sildenafil, vardenafil and tadalafil.

At present, there is no satisfactory specific drug for COVID-19; thus, it is important to improve systemic immune function in the context of viral infection. Furthermore, it is necessary to effectively intervene in a series of pathophysiological processes and inflammatory products caused by infection, including improvement of local tissue blood circulation disorder, tissue hypoxia, vascular endothelial damage and oxidative stress injury (20). Based on the pharmacological mechanism of action of PDE5Is, these drugs have unique value in the treatment of infectious diseases and may be effective 


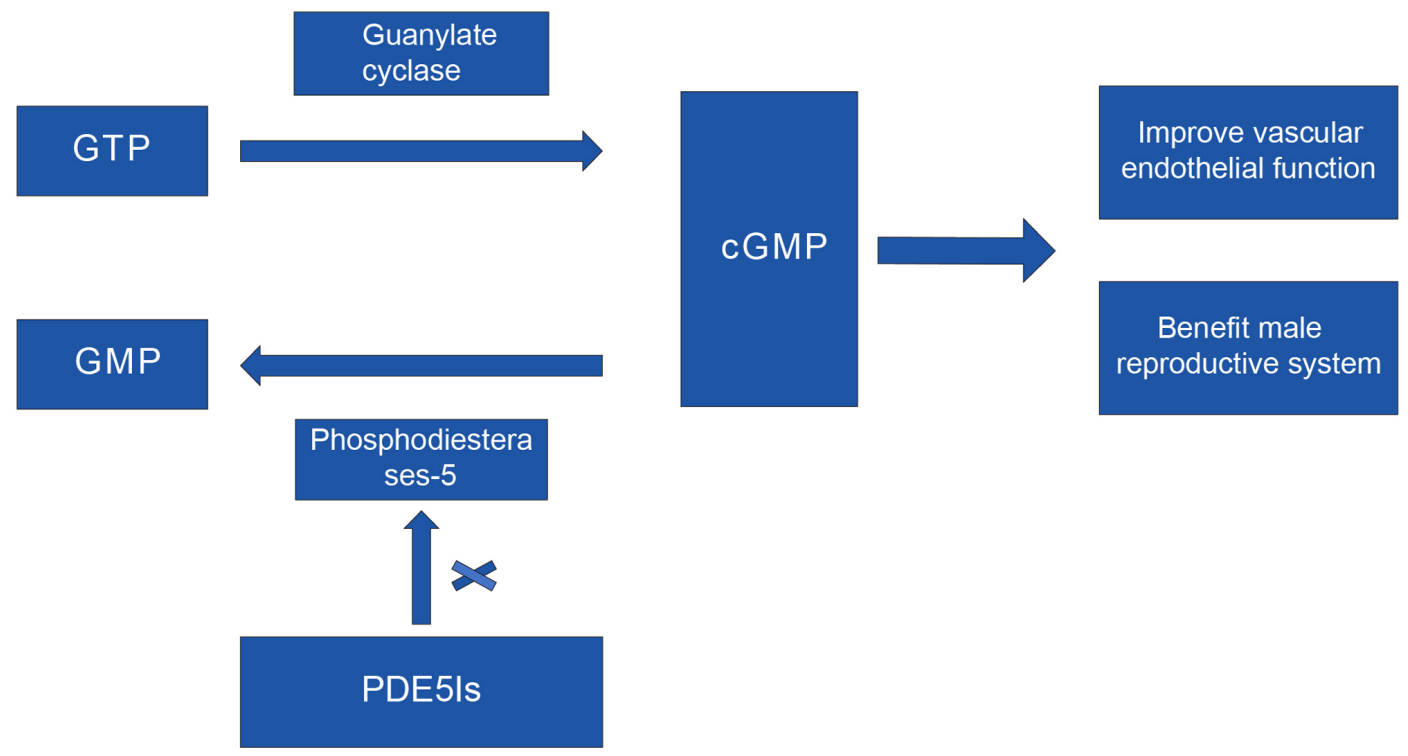

Figure 1. Detailed mechanism of action of PDE5Is. PDE5Is, phosphodiesterase-5 inhibitors; cGMP, cyclic guanosine monophosphate; GTP, guanosine triphosphate.

in combination with direct antiviral drugs. The anti-infection mechanism of PDE5Is in COVID-19 is presented in Fig. 2. The mechanism shown in the Fig. 2 is as follow: COVID-19 can cause adverse effects on human body by reducing immunity, enhancing inflammatory responses and reducing vascular endothelial function. But PDE5Is can synergistically treat COVID-19 by enhancing immunity, reducing inflammatory response and enhancing vascular endothelial function.

Enhancement of immunity. PDE5Is are able to enhance immune function. In healthy male mice treated with sildenafil, the percentage of $\mathrm{CD}^{+} \mathrm{T}$ cells was indicated to be decreased, while the percentage of $\mathrm{CD}^{+} \mathrm{T}$ cells was increased. It was also observed that the levels of effector memory and central memory $\mathrm{T}$ cells were decreased in male mice but increased in female mice. The percentages of activated natural killer (NK) cells and $\mathrm{T}$ cells were increased in female mice but decreased in male mice. In addition, sildenafil decreased the level of serum IL-6 and increased the level of IL-2. These results suggest that sildenafil has sex-specific immunoregulatory properties (21). Furthermore, the effects of sildenafil on thymocytes, splenocytes and $\mathrm{T}$ cells isolated from the lymph nodes of mice were studied. Oral sildenafil $(1 \mathrm{mg} / \mathrm{kg})$ temporarily reduced the percentage of $\mathrm{CD}^{+} \mathrm{CD}^{+}$thymocytes and increased that of $\mathrm{CD} 8^{+}$cells. In lymphocytes isolated from the mesenteric lymph nodes, the percentage of $\mathrm{CD}_{1} 9^{+}$cells was decreased and the percentage of $\mathrm{CD}^{+}$cells was increased $72 \mathrm{~h}$ after the last administration (22). Certain studies have indicated that sildenafil increases the production of IL-1 $\beta$ and NO in peritoneal macrophages and the percentage of phagocytes and decreases the percentage of monocytes (23). In a study on experimental autoimmune encephalomyelitis, a multiple sclerosis model, it was determined that sildenafil was able to reduce cell infiltration in the spinal cord and white matter of mice. Sildenafil increased the number of YM-1 cells (which is a marker of the alternative macrophage/microglial M2 phenotype that has neuroprotective and regenerative properties) and the expression of the granzyme $\mathrm{B}$ cluster in regulatory $\mathrm{T}$ cells (Tregs) (24). In addition, sildenafil

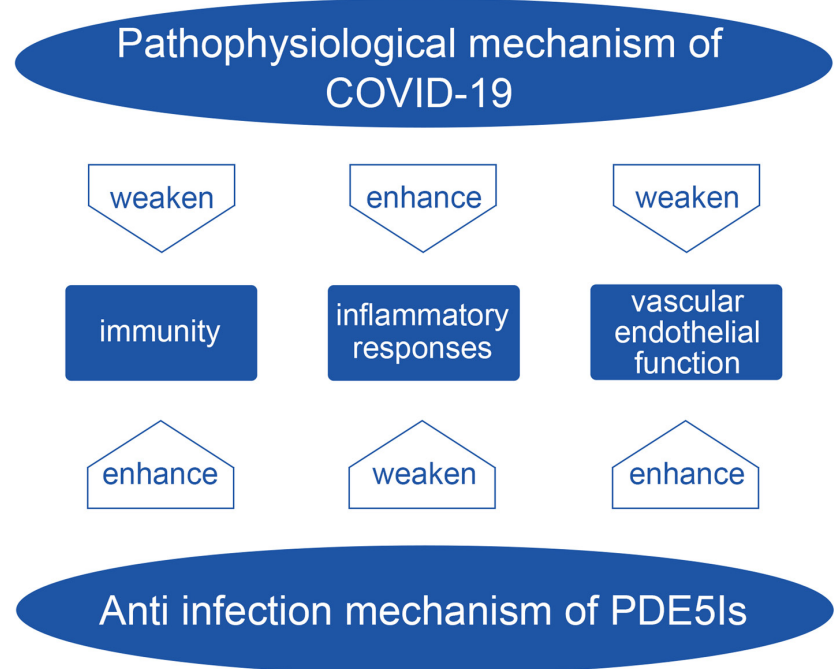

Figure 2. Anti-infection mechanism of PDE5Is in COVID-19. PDE5Is, phosphodiesterase-5 inhibitors; COVID-19, Coronavirus disease 19.

was able to prolong the survival time of tumour-bearing mice by enhancing antitumour immunity, which is achieved by inhib-

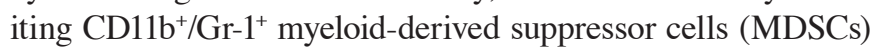
and downregulating IL-4 receptor $\alpha$ expression $(25,26)$.

Certain studies have indicated that sildenafil may significantly reduce the activity of NK cells in the peripheral blood of females with recurrent abortion and endometrial thickness significantly increases after treatment (27). A case of B-cell chronic lymphoblastic leukaemia (B-CLL) treated with sildenafil alone was reported. During the 3.5-year period of treatment with sildenafil (50 $\mathrm{mg} /$ week), the lymphocyte count of the patient decreased significantly and sildenafil induced apoptosis in B-CLL cells in a caspase-3-dependent manner (28). In addition, sildenafil may affect angiogenesis, platelet activation, Treg proliferation, proinflammatory cytokines and autoantibodies, thus affecting the innate and adaptive immune systems of experimental animals and patients (29). 
Anti-inflammatory responses. PDE5Is may also limit inflammatory factor activity and inflammatory responses and have anti-infection effects. It has been reported that F508del-CF mice exhibit a potential inflammatory state characterized by neutrophil infiltration and mouse macrophage inflammatory protein 2 and TNF- $\alpha$ expression. Intraperitoneal administration of vardenafil was indicated to significantly reduce the inflammatory response of F508del-CF mice and decrease macrophage infiltration, macrophage chemokine levels and IL-1 $\beta$ levels. These results suggest that vardenafil may significantly reduce lung inflammation in F508del-CF mice, particularly in terms of macrophage markers (30). Another study indicated that vardenafil is able to reduce the proinflammatory and fibrotic functions of fibroblasts in mice with cystic fibrosis, providing convincing novel support for developing a drug therapy to target the cGMP signalling pathway in cystic fibrosis (31). It has also been reported that tadalafil is able to reduce the levels of malondialdehyde and NO in the kidneys of rats with acute pyelonephritis and enhance the activities of superoxide dismutase (SOD) and catalase. These results suggest that tadalafil may improve the levels of circulating inflammatory cytokines, reverse oxidative dysfunction and ultimately protect the kidneys (32). In addition, in an acute lung injury (ALI) model, sildenafil treatment reduced cell leakage, particularly neutrophil infiltration into the lungs, decreased the release of proinflammatory mediators (TNF- $\alpha$, IL-8 and IL-6) and the levels of nitrite/nitrate and oxidative damage markers, reduced the formation of pulmonary oedema and improved respiratory parameters. Therefore, sildenafil also has a potential role in the treatment of ALI (33).

In a rat model of bronchopulmonary dysplasia, prophylactic treatment with sildenafil was indicated to significantly increase cGMP levels in the lungs, reduce the pulmonary inflammatory response, fibrin deposition and right ventricular hypertrophy and to stimulate alveolarization (34). In addition, oral administration of tadalafil $(1 \mathrm{mg} / \mathrm{kg})$ for 8 weeks was able to significantly improve silica-induced lung injury. The protective effect of tadalafil is related to the inhibition of cytokine expression in inflammation and fibrosis, recovery of the antioxidant capacity and promotion of angiogenesis (35). It has been indicated that in a rat model of lipopolysaccharide-induced sepsis, sildenafil may increase the level of glutathione, reduce the activities of myeloperoxidase (MPO), lipid peroxidase and SOD and to decrease the level of serum TNF- $\alpha$ and the inflammatory score. Therefore, sildenafil has protective effects on the lung and kidney damage caused by sepsis (36). In addition, tadalafil may prevent or slow ureteral inflammation and urothelial degeneration in rats with ureteral obstruction and reduce the expression of $\alpha$-smooth muscle actin and transforming growth factor- $\beta$ (37).

$\mathrm{T}$ helper 1 (Th1)-type cytokines and chemokines are bioactive mediators in the inflammatory response and the Th1 chemokine C-X-C motif chemokine ligand (CXCL)10 is involved in the occurrence and development of cardiac injury. In diabetic subjects with cardiomyopathy, sildenafil was able to significantly reduce the protein secretion and gene expression of CXCL10 in human cardiomyocytes and reduce the level of CXCL10 in patients (38). Cavernitis is a rare acute infection of the penis. If not treated properly, cavernitis may lead to cavernous abscess formation, fibrosis and subsequent erectile dysfunction. In a clinical study, two patients with cavernitis were treated with antibiotics and tadalafil and their clinical symptoms improved rapidly. After 3 months of follow-up, the erectile function of the patients was normal and there was no penile scarring. This suggests that tadalafil may have a synergistic effect with antibacterial therapy (39). In addition, the therapeutic effect of vardenafil combined with antibiotics in the treatment of patients with chronic bacterial prostatitis (CBP) was studied. The National Institutes of Health-Chronic Prostatitis Symptom Index (NIH-CPSI) scale, urinary bacteria and leukocyte counts and the urine flow rate were used to evaluate the therapeutic effect. It was indicated that the combination of antibiotics and vardenafil achieved a significantly improved efficacy in CBP (40). In addition, a study reported that in a patient with a severe chronic foot wound, the wound healed almost completely after treatment with tadalafil (20 mg three times a day) and was stable for 2 years, which unexpectedly revealed a role for tadalafil in chronic wound infection treatment (41).

Improvement of vascular endothelial function. PDE5Is relax vascular smooth muscle and improve the local blood circulation. Certain studies have explored the therapeutic effect of sildenafil in the early stage of sepsis. Sildenafil may increase the renal blood flow, decrease pulmonary MPO activity and reduce the levels of plasma creatinine, lactate and creatine kinase. Therefore, sildenafil may be a treatment for early sepsis (42). In addition, the effects of intraperitoneal injection of sildenafil on left colonic anastomosis healing and intra-abdominal adhesion formation were also studied. The healing of an anastomotic stoma in model rats was significantly improved and histopathological results indicated that angiogenesis was increased and intra-abdominal adhesion was significantly reduced (43). Severe endothelial cell injury is the key event in the process of ischaemia-reperfusion (I/R) injury. It was indicated that sildenafil may dilate blood vessels and increase the cGMP level, but was not able to affect the recovery of renal function or I/R injury (44). In addition, sildenafil may prevent early transplantation failure, prolong ischaemic tolerance and improve lung function in pigs with lung I/R injury (45). Furthermore, a study reported that for patients with benign prostatic hyperplasia, $5 \mathrm{mg}$ tadalafil may relax the vascular smooth muscle, improve vascular endothelial function and increase vascular elasticity (46). The effect of sildenafil on the microvascular blood flow in patients with systemic sclerosis secondary to Raynaud's phenomenon (RP) was also explored in one study. The results suggested that sildenafil improved the finger artery blood flow and RP symptoms after 8 weeks of treatment, which indicates that sildenafil is a good choice for the treatment of secondary RP (47).

Studies have also investigated the effect of sildenafil on AngII-dependent hypertension and renal vascular dysfunction. It was indicated that sildenafil is able to lower AngII-dependent hypertension and enhance NO-mediated vasodilation, which is a key regulator of renal haemodynamics in patients with hypertension (48). In addition, there the effects of sildenafil on irisin levels in the heart, liver and kidney tissues were explored and it was evaluated whether sildenafil impacts serum irisin or NO levels in rats with induced experimental myocardial ischaemia. Sildenafil was effective in eliminating 
ischaemia and may be the first choice for offsetting the effects of ischaemia in the future (49). Studies have also explored the effects of vardenafil on the systemic endothelial function of diabetic patients with erectile dysfunction. Chronic vardenafil administration was able to significantly improve endothelial parameters in diabetic patients (50). Whether sildenafil is able to improve tissue perfusion and neovascularization and downregulate proinflammatory molecules following limb ischaemia has also been examined. Sildenafil was able to significantly improve tissue perfusion and the inflammatory status after limb ischaemia, which implies that sildenafil potentially has properties related to neovascularization and vascular protection (51). Studies exploring the effects of sildenafil on cerebrovascular function and cerebral metabolism in patients with Alzheimer's disease (AD) have also been performed. After sildenafil administration, the cerebral blood flow and cerebral oxygen metabolism rate of the patients were significantly increased (52). Furthermore, numerous studies have confirmed that sildenafil is able to significantly improve pulmonary hypertension and relax blood vessels $(53,54)$.

\section{Roles of PDE5Is in COVID-19}

Combination treatment of COVID-19. COVID-19 may promote the induction of endothelial inflammation in multiple organs, which is the direct result of SARS-CoV-2 infection and host inflammatory response activation. This progressive endothelial thrombotic inflammatory syndrome involves the microvessels of numerous important organs, leading to multiorgan failure and death; this syndrome is also the mechanism underlying interstitial pneumonia developing into pulmonary failure. As a vasodilator, tadalafil may be administered once a day to improve tissue angiogenesis and anti-fibrotic function, thus blocking or preventing vascular endothelial sclerosis in patients with COVID-19 (55). There is a strong correlation between the severity of infection caused by COVID-19 and the presence of hypertension and numerous studies have demonstrated that hypertension is related to NO. Considering the pharmacology of PDE5Is, these drugs may be used as early complimentary drugs in the treatment of COVID-19 (56). Furthermore, numerous patients with COVID-19 have symptoms of bilateral diffuse alveolar injury and pulmonary oedema, increased levels of proinflammatory mediators and elevated pulmonary capillary pressure. Whether PDE5Is should be included in combination treatments of COVID-19 to facilitate the recovery of patients has also been considered (57). Certain studies have indicated that NO may alleviate lung injury, reduce the concentrations of proinflammatory cytokines and decrease the number of neutrophils entering the lungs. Therefore, PDE5Is may be used to increase the level of NO as part of the treatment of COVID-19 (58). The use of PDE5Is to reduce pulmonary hypertension and relieve the symptoms of acute respiratory distress syndrome and the used of PDE5Is for synergistic treatment of COVID-19 have also been proposed (59).

Therefore, PDE5Is also have important roles in protecting against infectious diseases. PDE5Is may improve the treatment of infectious diseases by enhancing immunity and anti-inflammatory responses and improving vascular endothelial function. In patients with COVID-19, PDE5Is may be considered as synergistic drugs for combined treatment.

Multiple beneficial effects for COVID-19. Various studies have indicated that COVID-19 has potential adverse effects on the male reproductive system $(60,61)$. ACE2 is expressed in the spermatogonia, Leydig cells and Sertoli cells of the testes. SARS-CoV-2 may cause reproductive dysfunction in patients via the ACE2 pathway (62). Certain studies have indicated that patients with COVID-19 have symptoms of viral orchitis and scrotal discomfort, which have a negative impact on male reproductive function and spermatogenesis (63). Certain studies have also summarized the adverse effects of SARS-CoV-2 on male reproductive health, which may lead to testicular damage and male infertility and suggest the theoretical possibility of sexual transmission, as SARS-CoV-2 has been identified in the semen of infected patients. It is also necessary to rehabilitate and monitor the reproductive system of patients with COVID-19 $(64,65)$.

PDE5Is may improve vascular endothelial function, promote the testicular and systemic blood circulation and testosterone secretion and improve epididymal function, sperm maturation and capacitation $(66,67)$. Therefore, in view of the possible damage to the male reproductive system and whole body caused by SARS-CoV-2, PDE5Is may be considered for inclusion in combined therapy to treat COVID-19, which may improve orchitis and sperm quality while enhancing systemic antiviral effects. In general, PDE5Is are safe in clinical practice. The incidence of side effects is low (from 9 to 25\%), the symptoms are not serious and most symptoms are tolerable, and PDE5Is may be obtained from a pharmacy with a prescription. The potential side effects of PDE5Is include headache, flushing, dyspepsia, nasal congestion, dizziness, abnormal vision, back pain and myalgia. The absolute contraindication is combined use with nitrates (68). For patients with COVID-19 with damage to male reproductive function or erectile dysfunction, the combined use of PDE5Is may not only help to treat the viral infection but also benefit reproductive function. For patients with COVID-19 without damage to male reproductive function or erectile dysfunction, the combined use of PDE5Is may prevent damage to the male reproductive system.

\section{Conclusion}

COVID-19 has certain adverse effects on numerous parts of the human body, including the respiratory system and male reproductive system. PDE5Is with a variety of anti-infection mechanisms may become important drugs for combination therapy, particularly in patients with male genital infection, and the combined use of PDE5Is may achieve multiple beneficial effects.

\section{Acknowledgements}

Not applicable.

\section{Funding}

This study was supported by a grant from the CAMS Innovation Fund for Medical Sciences CIFMS (no. 2018-I2M-1-004) . 


\section{Availability of data and materials}

Not applicable.

\section{Authors' contributions}

HS, CM and HL were involved in the acquisition, analysis and interpretation of the data. HS and HL also contributed to the design and conception of the study. HS drafted the manuscript. All authors read and approved the final manuscript.

\section{Ethics approval and consent to participate}

Not applicable.

\section{Patient consent for publication}

Not applicable.

\section{Competing interests}

The authors declare that they have no competing interests.

\section{References}

1. Wu F, Zhao S, Yu B, Chen YM, Wang W, Song ZG, Hu Y, Tao ZW, Tian JH, Pei YY, et al: A new coronavirus associated with human respiratory disease in China. Nature 579: 265-269, 2020.

2. Chakraborty C, Sharma AR, Sharma G, Bhattacharya M and Lee SS: SARS-CoV-2 causing pneumonia-associated respiratory disorder (COVID-19): Diagnostic and proposed therapeutic options. Eur Rev Med Pharmacol Sci 24: 4016-4026, 2020.

3. Liu X, Liu C, Liu G, Luo W and Xia N: COVID-19: Progress in diagnostics, therapy and vaccination. Theranostics 10: 7821-7835, 2020 .

4. Samavati $\mathrm{L}$ and Uhal BD: ACE2, much more than just a receptor for SARS-COV-2. Front Cell Infect Microbiol 10: 317, 2020.

5. Yan R, Zhang Y, Li Y, Xia L, Guo Y and Zhou Q: Structural basis for the recognition of SARS-CoV-2 by full-length human ACE2. Science 367: 1444-1448, 2020

6. Hoffmann M, Kleine-Weber H, Schroeder S, Krüger N, Herrler T, Erichsen S, Schiergens TS, Herrler G, Wu NH, Nitsche A, et al SARS-CoV-2 cell entry depends on ACE2 and TMPRSS2 and is blocked by a clinically proven proteaseinhibitor. Cell 181 271-280.e8, 2020.

7. Roca-Ho H, Riera M, Palau V, Pascual J and Soler MJ: Characterization of ACE and ACE2 expression within different organs of the NOD mouse. Int J Mol Sci 18: 563, 2017.

8. Das UN: Renin-angiotensin-aldosterone system in insulin resistance and metabolic syndrome. J Transl Int Med 4: 66-72, 2016.

9. Kato H, Hou J, Chobanian AV and Brecher P: Effects of angiotensin II infusion and inhibition of nitric oxide synthase on the rat aorta. Hypertension 28: 153-158, 1996.

10. Santos RA, Simoes e Silva AC, Maric C, Silva DM, Machado RP, de Buhr I, Heringer-Walther S, Pinheiro SV, Lopes MT, Bader M, et al: Angiotensin-(1-7) is an endogenous ligand for the G protein-coupled receptor Mas. Proc Natl Acad Sci USA 100: 8258-8263, 2003.

11. Fraga-Silva RA, Sorg BS, Wankhede M, Dedeugd C, Jun JY, Baker MB, Li Y, Castellano RK, Katovich MJ, Raizada MK, et al: ACE2 activation promotes antithrombotic activity. Mol Med 16: 210-215, 2010

12. Tikellis $\mathrm{C}$ and Thomas MC: Angiotensin-converting enzyme 2 (ACE2) is a key modulator of the renin angiotensin system in health and disease. Int J Pept 2012: 256294, 2012.

13. Wang $\mathrm{Z}$ and $\mathrm{Xu} X$ : scRNA-seq profiling of human testes reveals the presence of the ACE2 receptor, a target for SARS-CoV-2 infection in Spermatogonia, Leydig and Sertoli cells. Cells 9 : 920, 2020.
14. Illiano E, Trama F and Costantini E: Could COVID-19 have an impact on male fertility? Andrologia 52: e13654, 2020.

15. Li D, Jin M, Bao P, Zhao W and Zhang S: Clinical characteristics and results of semen tests among men with coronavirus disease 2019. JAMA Netw Open 3: e208292, 2020.

16. Holtmann N, Edimiris P, Andree M, Doehmen C, Baston-Buest D, Adams O, Kruessel JS and Bielfeld AP: Assessment of SARS-CoV-2 in human semen-a cohort study. Fertil Steril 114: 233-238, 2020.

17. Yang M, Chen S, Huang B, Zhong JM, Su H, Chen YJ, Cao Q, Ma L, He J, Li XF, et al: Pathological findings in the testes of COVID-19 patients: Clinical implications. Eur Urol Focus 6: 1124-1129, 2020.

18. Lue TF: Erectile dysfunction. N Engl J Med 342: 1802-1813, 2000

19. Cai Z, Zhang J and Li H: Two birds with one stone: Regular use of PDE5 inhibitors for treating male patients with erectile dysfunction and cardiovascular diseases. Cardiovasc Drugs Ther 33: 119-128, 2019.

20. Tay MZ, Poh CM, Rénia L, MacAry PA and Ng LF: The trinity of COVID-19: Immunity, inflammation and intervention. Nat Rev Immunol 20: 363-374, 2020.

21. Karakhanova S, Yang Y, Link J, Soltek S, von Ahn K, Umansky V, Werner J and Bazhin AV: Gender-specific immunological effects of the phosphodiesterase 5 inhibitor sildenafil in healthy mice. Mol Immunol 56: 649-659, 2013.

22. Szczypka M and Obmińska-Mrukowicz B: Modulating effects of nonselective and selective phosphodiesterase inhibitors on lymphocyte subsets and humoral immune response in mice. Pharmacol Rep 62: 1148-1158, 2010

23. Szczypka M and Obmińska-Mrukowicz B: The effects of selective and nonselective phosphodiesterase inhibitors on phagocytic cells in mice. Immunopharmacol Immunotoxicol 32: 507-513, 2010.

24. Pifarré P, Gutierrez-Mecinas M, Prado J, Usero L, Roura-Mir C, Giralt M, Hidalgo J and García A: Phosphodiesterase 5 inhibition at disease onset prevents experimental autoimmune encephalomyelitis progression through immunoregulatory and neuroprotective actions. Exp Neurol 251: 58-71, 2014.

25. Serafini P, Meckel K, Kelso M, Noonan K, Califano J, Koch W, Dolcetti L, Bronte V and Borrello I: Phosphodiesterase-5 inhibition augments endogenous antitumor immunity by reducing myeloid-derived suppressor cell function. J Exp Med 203: 2691-2702, 2006

26. Meyer C, Sevko A, Ramacher M, Bazhin AV, Falk CS, Osen W, Borrello I, Kato M, Schadendorf D, Baniyash M, et al: Chronic inflammation promotes myeloid-derived suppressor cell activation blocking antitumor immunity in transgenic mouse melanoma model. Proc Natl Acad Sci USA 108: 17111-17116, 2011.

27. Jerzak M, Kniotek M, Mrozek J, Górski A and Baranowski W: Sildenafil citrate decreased natural killer cell activity and enhanced chance of successful pregnancy in women with a history of recurrent miscarriage. Fertil Steril 90: 1848-1853, 2008

28. Sarfati M, Mateo V, Baudet S, Rubio M, Fernandez C, Davi F, Binet JL, Delic J and Merle-Beral H: Sildenafil and vardenafil, types 5 and 6 phosphodiesterase inhibitors, induce caspase-dependent apoptosis of B-chronic lymphocytic leukemia cells. Blood 101: 265-269, 2003.

29. Kniotek M and Boguska A: Sildenafil can affect innate and adaptive immune system in both experimental animals and patients. J Immunol Res 2017: 4541958, 2017.

30. Lubamba B, Huaux F, Lebacq J, Marbaix E, Dhooghe B, Panin N, Wallemacq P and Leal T: Immunomodulatory activity of vardenafil on induced lung inflammation in cystic fibrosis mice. J Cyst Fibros 11: 266-273, 2012.

31. Huaux F, Noel S, Dhooghe B, Panin N, Lo Re S, Lison D, Wallemacq P, Marbaix E, Scholte BJ, Lebecque P, et al: Dysregulated proinflammatory and fibrogenic phenotype of fibroblasts in cystic fibrosis. PLoS One 8: e64341, 2013.

32. Zhu CY, Liu M, Liu YZ, Li W, Zhai W, Che JP, Yan Y, Wang GC and Zheng JH: Preventive effect of phosphodiesterase 5 inhibitor tadalafil on experimental post-pyelonephritic renal injury in rats. J Surg Res 186: 253-261, 2014.

33. Kosutova P, Mikolka P, Balentova S, Kolomaznik M, Adamkov M, Mokry J, Calkovska A and Mokra D: Effects of phosphodiesterase 5 inhibitor sildenafil on the respiratory parameters, inflammation and apoptosis in a saline lavage-induced model of acute lung injury. J Physiol Pharmacol 69: 2018.

34. de Visser YP, Walther FJ, Laghmani H, Boersma $\mathrm{H}$, van der Laarse A and Wagenaar GT: Sildenafil attenuates pulmonary inflammation and fibrin deposition, mortality and right ventricular hypertrophy in neonatal hyperoxic lung injury. Respir Res 10: 30, 2009. 
35. Abdelaziz RR, Elkashef WF and Said E: Tadalafil reduces airway hyperactivity and protects against lung and respiratory airways dysfunction in a rat model of silicosis. Int Immunopharmacol 40 530-541, 2016

36. Cadirci E, Halici Z, Odabasoglu F, Albayrak A, Karakus E, Unal D, Atalay F, Ferah I and Unal B: Sildenafil treatment attenuates lung and kidney injury due to overproduction of oxidant activity in a rat model of sepsis: A biochemical and histopathological study. Clin Exp Immunol 166: 374-384, 2011.

37. Köktürk S, Benli E, Ayyıldız A, Cırrık S, Cetinkol Y, Ayyıldız SN and Noyan T: Positive outcomes of phosphodiesterase type 5 inhibitor on histopathologic and biochemical changes induced by ureteral obstruction. Rev Assoc Med Bras (1992) 65: 388-393, 2019.

38. Di Luigi L, Corinaldesi C, Colletti M, Scolletta S, Antinozzi C, Vannelli GB, Giannetta E, Gianfrilli D, Isidori AM Migliaccio S, et al: Phosphodiesterase type 5 inhibitor sildenafil decreases the proinflammatory chemokine CXCL10 in human cardiomyocytes and in subjects with diabetic cardiomyopathy. Inflammation 39: 1238-1252, 2016.

39. Bakhsh A, Daqqaq T, Alhasan A, Alnazari M and Rajih E: The role of phosphodiesterase inhibitors in the management of cavernositis with multifocal abscesses: A report of case series. Sex Med 8: 318-322, 2020

40. Aliaev IuG, Vinarov AZ and Akhvlediani ND: Wardenafil in combined treatment of patients with chronic bacterial prostatitis. Urologiia 6: 52-55, 2008 (In Russian).

41. Davenport $C$ and Dubin A: Tadalafil therapy and severe chronic foot wound resolution. Int Wound J 12: 733-736, 2015.

42. Kovalski V, Prestes AP, Oliveira JG, Alves GF, Colarites DF Mattos JE, Sordi R, Vellosa JC and Fernandes D: Protective role of cGMP in early sepsis. Eur J Pharmacol 807: 174-181, 2017.

43. Ayten R, Cetinkaya Z, Girgin M, Ozercan I, Ustundag B and Aygen E: The effects of intraperitoneal sildenafil administration on healing of left colonic anastomoses and intra-abdominal adhesion formation in the presence of intra-abdominal infection. Dis Colon Rectum 51: 1837-1841, 2008.

44. Hosgood SA, Randle LV, Patel M, Watson CJ, Bradley JA and Nicholson ML: Sildenafil citrate in a donation after circulatory death experimental model of renal ischemia-reperfusion injury. Transplantation 98: 612-617, 2014

45. Korom S, Hillinger S, Cardell M, Zhai W, Tan Q, Dutly A, Leskosek B and Weder W: Sildenafil extends survival and graft function in a large animal lung transplantation model. Eur J Cardiothorac Surg 29: 288-293, 2006.

46. Amano T, Earle C, Imao T, Matsumoto $\mathrm{Y}$ and Kishikage $\mathrm{T}$ Administration of daily $5 \mathrm{mg}$ tadalafil improves endothelial function in patients with benign prostatic hyperplasia. Aging Male 21: 77-82, 2018.

47. Andrigueti FV, Ebbing PCC, Arismendi MI and Kayser C: Evaluation of the effect of sildenafil on the microvascular blood flow in patients with systemic sclerosis: A randomised, double-blind, placebo-controlled study. Clin Exp Rheumatol 35 (Suppl 106): 151-158, 2017.

48. Thieme M, Sivritas SH, Mergia E, Potthoff SA, Yang G, Hering L, Grave K, Hoch H, Rump LC and Stegbauer J: Phosphodiesterase 5 inhibition ameliorates angiotensin II-dependent hypertension and renal vascular dysfunction. Am J Physiol Renal Physiol 312: F474-F481, 2017.

49. Aydin S, Kuloglu T, Aydin S, Yardim M, Azboy D, Temizturk Z, Kalkan AK and Eren MN: The effect of iloprost and sildenafil, alone and in combination, on myocardial ischaemia and nitric oxide and irisin levels. Cardiovasc J Afr 28: 389-396, 2017.

50. Santi D, Granata AR, Guidi A, Pignatti E, Trenti T, Roli L, Bozic R, Zaza S, Pacchioni C, Romano S, et al: Six months of daily treatment with vardenafil improves parameters of endothelial inflammation and of hypogonadism in male patients with type 2 diabetes and erectile dysfunction: A randomized, double-blind, prospective trial. Eur J Endocrinol 174: 513-522, 2016.

51. Valatsou A, Briasoulis A, Vogiatzi G, Pantopoulou A, Oikonomou E, Miliou A, Perrea D and Tousoulis D: Beneficial effects of sildenafil on tissue perfusion and inflammation in a murine model of limb ischemia and atherosclerosis. Curr Vasc Pharmacol 15: 282-287, 2017.
52. Sheng M, Lu H, Liu P, Li Y, Ravi H, Peng SL, Diaz-Arrastia R, Devous MD and Womack KB: Sildenafil improves vascular and metabolic function in patients with Alzheimer's disease. J Alzheimers Dis 60: 1351-1364, 2017.

53. Palma G, Giordano R, Russolillo V, Cioffi S, Palumbo S, Mucerino M, Poli V and Vosa C: Sildenafil therapy for pulmonary hypertension before and after pediatric congenital heart surgery. Tex Heart Inst J 38: 238-242, 2011.

54. Kelly LE, Ohlsson A and Shah PS: Sildenafil for pulmonary hypertension in neonates. Cochrane Database Syst Rev 8: CD005494, 2017.

55. Mondaini N: Phosphodiesterase type 5 inhibitors and COVID-19: are they useful in disease management? World J Mens Health 38 254-255, 2020

56. Dal Moro F and Livi U: Any possible role of phosphodiesterase type 5 inhibitors in the treatment of severe COVID19 infections? A lesson from urology. Clin Immunol 214: 108414, 2020.

57. Solaimanzadeh I: Acetazolamide, nifedipine and phosphodiesterase inhibitors: Rationale for their utilization as adjunctive countermeasures in the treatment of coronavirus disease 2019 (COVID-19). Cureus 12: e7343, 2020.

58. Dal Moro F, Vendramin I and Livi U: The war against the SARS-CoV2 infection: Is it better to fight or mitigate it? Med Hypotheses 143: 110129, 2020.

59. Reinert JP and Reinert NJ: The role of phosphodiesterase-5 inhibitors in COVID-19: An exploration of literature from similar pathologies. J Intensive Care Med 36: 3-8, 2020.

60. Groner MF, de Carvalho RC, Camillo J, Ferreira PR and Fraietta R: Effects of Covid-19 on male reproductive system. Int Braz J Urol 47: 185-190, 2021.

61. Batiha O, Al-Deeb T, Al-Zoubi E and Alsharu E: Impact of COVID-19 and other viruses on reproductive health. Andrologia 52: e13791, 2020

62. Shen Q, Xiao X, Aierken A, Yue W, Wu X, Liao M and Hua J: The ACE2 expression in Sertoli cells and germ cells may cause male reproductive disorder after SARS-CoV-2 infection. J Cell Mol Med 24: 9472-9477, 2020.

63. Pan F, Xiao X, Guo J, Song Y, Li H, Patel DP, Spivak AM, Alukal JP, Zhang X, Xiong C, et al: No evidence of severe acute respiratory syndrome-coronavirus 2 in semen of males recovering from coronavirus disease 2019. Fertil Steril 113: 1135-1139, 2020.

64. Fraietta R, Pasqualotto FF, Roque $M$ and Taitson PF: SARS-COV-2 and male reproductive health. JBRA Assist Reprod 24: 347-350, 2020.

65. Khalili MA, Leisegang K, Majzoub A, Finelli R, Panner Selvam MK, Henkel R, Mojgan M and Agarwal A: Male fertility and the COVID-19 pandemic: Systematic review of the literature. World J Mens Health 38: 506-520, 2020.

66. Sofikitis N, Kaltsas A, Dimitriadis F, Rassweiler J, Grivas N, Zachariou A, Kaponis A, Tsounapi P, Paterakis N, Karagiannis A, et al: The Effect of PDE5 inhibitors on the male reproductive tract. Curr Pharm Des: Feb 26, 2020 (Epub ahead of print). doi: 10.2174/1381612826666200226121510.

67. Corvasce A, Albino G, Leonetti T, Buonomo AF and Marucco EC Once-a-day Tadalafil administration improves the spermogram parameters in fertile patients. Arch Ital Urol Androl 87: 210-213, 2015.

68. Yuan J, Zhang R, Yang Z, Lee J, Liu Y, Tian J, Qin X, Ren Z, Ding H, Chen Q, et al: Comparative effectiveness and safety of oral phosphodiesterase type 5 inhibitors for erectile dysfunction: A systematic review and network meta-analysis. Eur Urol 63: 902-912, 2013

c) (7) $\odot$ This work is licensed under a Creative Commons Attribution-NonCommercial-NoDerivatives 4.0 International (CC BY-NC-ND 4.0) License. 